\title{
PROJEKTOWANIE PRAW STEROWANIA LOTEM GRUPOWYM BEZZAŁOGOWYCH APARATÓW LATAJĄCYCH
}

\begin{abstract}
Bezzałogowe aparaty latające (BAL) są obecnie wykorzystywane przez człowieka do różnorodnych zadań militarnych i cywilnych. Możemy tutaj wymienić m. in. zadania takie jak zwiad i rozpoznanie nad terytorium wroga, ocena szkód po działaniach wojennych, kontrolowanie ruchu ulicznego, patrolowanie granic państwa, monitorowanie upraw rolniczych, zliczanie dzikiej zwierzyny na dużych obszarach leśnych oraz wiele innych. Wszystkie te zadania mogą zostać wykonane szybciej i efektywniej przez grupę BAL połączonych wspólnym prawem sterowania. Implementacja praw sterowania lotem grupowym powinna być poprzedzona wnikliwą analizą tworzonego algorytmu sterowania oraz jego licznymi badaniami symulacyjnymi pozwalającymi na weryfikację proponowanego podejścia. $\mathrm{W}$ artykule przedstawiono problem sterowania lotem grupowy BAL. Zaprezentowano opracowaną metodę sterowania lotem grupowym BAL opartą o układ Leader/Follower. W oparciu o założony model dynamiki pojedynczego obiektu (mikro-samolotu) zbudowano model symulacyjny w środowisku Matlab/Simulink z użyciem przyborników Control, Flight Dynamics and Control oraz Aerospace. Pokazane zostały matematyczne podstawy tej metody oraz zaprezentowano proces projektowania praw sterowania grupą BAL. Następnie dokonano weryfikacji zaprojektowanych praw sterowania. Przeprowadzono szereg badań symulacyjnych a ich wyniki zaprezentowano w formie wykresów przedstawiających przebiegi czasowe parametrów nawigacyjnych Leader'a oraz Follower'a (prędkość, kierunek, wysokość, tor lotu, profil lotu). Uzyskane wyniki pozwalają ocenić słuszność przyjętego procesu projektowania praw sterowania oraz ich efektywność a także możliwość implementacji na komputerze pokładowym mikrosamolotu.
\end{abstract}

Słowa kluczowe: bezzałogowe aparaty latające, sterowanie lotem, parametry nawigacyjne

\footnotetext{
${ }^{1}$ Autor do korespondencji/corresponding author: Leszek Ambroziak, Politechnika Białostocka, Wydział Mechaniczny, ul. Wiejska 45C, 15-351 Białystok, e-mail: l.ambroziak@pb.edu.pl

${ }^{2}$ Zdzisław Gosiewski, Politechnika Białostocka, Wydział Mechaniczny, ul. Wiejska 45C, 15-351 Białystok, e-mail: z.gosiewski@pb.edu.pl
} 


\section{Wstęp}

Loty grupowe bezzałogowych aparatów latających są problemem obecnie bardzo intensywnie badanym $w$ różnych ośrodkach naukowych na świecie [1, 2]. Badania te dotyczą przede wszystkim zagadnień związanych $\mathrm{z}$ aerodynamiką lotu grupowego $([3,4,5]$, analizą nowoczesnych koncepcji sterowania [6] czy też syntezy praw sterowania (optymalnego [7], adaptacyjnego [8], ślizgowego [9], odpornego [10], opartego na informacji wizyjnej). Implementacja praw sterowania lotem grupowym powinna być poprzedzona wnikliwą analizą tworzonego algorytmu sterowania oraz jego licznymi badaniami symulacyjnymi pozwalającymi na weryfikację proponowanego podejścia. Tak przeprowadzony proces syntezy układu sterowania lotem pozwoli na jego pomyślną implementację oraz przeprowadzenie badań w locie.

Niniejsza praca dotyczy problemu sterowania lotem grupowy BAL. Zawarty został opis metody sterowania lotem grupowym BAL opartej o układ Leader. Głównym celem pracy były badania symulacyjne. Dokonano weryfikacji zaprojektowanych praw sterowania w drodze symulacji komputerowej. Przeprowadzono szereg badań i analiz algorytmy sterowania lotem grupowym. Wyniki zaprezentowano $\mathrm{w}$ formie wykresów przedstawiających przebiegi czasowe parametrów nawigacyjnych Leader'a oraz Follower'a. Otrzymane rezultaty pozwalają ocenić słuszność przyjętego procesu projektowania praw sterowania oraz ich efektywność a także możliwość implementacji na kontrolerze lotu grupowego.

\section{Obiekt badań}

\subsection{Mikro-samolot Twister}

Obiektem badań był mikro-samolot delta w układzie latającego skrzydła. Model ten pokazany został na rysunku 1 . Jest to model konstrukcyjny wykonany $\mathrm{z}$ drewna balsowego pokrytego folią. Napędzany jest on silnikiem elektrycznym umieszczonym $\mathrm{z}$ przodu. Płat skrzydła badanego samolotu posiada symetryczny, dwuwypukły profil BELL 540 (modyfikacja profilu NACA0012). Wymiary i ważniejsze parametry konstrukcyjne badanego mikro-samolotu zostały zawarte w tabeli 1. Mikro-samolot dodatkowo wyposażony jest $\mathrm{w}$ autopilot, radiomodem na pasmo ISM do komunikacji ze stacją naziemną, Fig. 1. Delta micro airplane

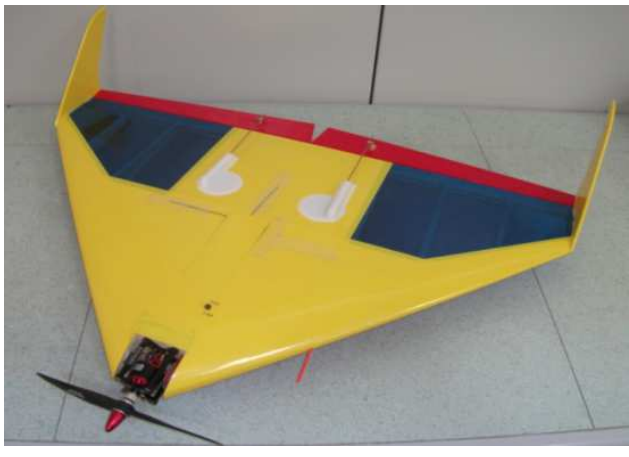

Rys. 1. Mikro-samolot delta 
układ zasilania bateryjnego, anteny GPS. Jego ważniejsze parametry zostały pokazane w tabeli 1 . Samolot ten był badany w tunelu aerodynamicznym Politechniki Rzeszowskiej w celu identyfikacji jego charakterystyk aerodynamicznych [11]. Pozostałe parametry aerodynamiczne były opublikowane w [12, 13].

Tabela 1. Parametry mikro-samolotu

Table 1. Parameters of the micro airplane

\begin{tabular}{|c|c|}
\hline Parametr & Wartość \\
\hline Rozpiętość skrzydeł & $0.840[\mathrm{~m}]$ \\
\hline Długość całkowita & $0.570[\mathrm{~m}]$ \\
\hline Masa modelu & $1.3[\mathrm{~kg}]$ \\
\hline $\begin{array}{c}\text { Powierzchnia } \\
\text { skrzydła }\end{array}$ & $0.296\left[\mathrm{~m}^{2}\right]$ \\
\hline $\begin{array}{c}\text { Srednia cięciwa } \\
\text { aerodynamiczna }\end{array}$ & $0.397[\mathrm{~m}]$ \\
\hline$I_{x}$ & $0.01841\left[\mathrm{kgm}^{2}\right]$ \\
\hline$I_{y}$ & $0.03672\left[\mathrm{kgm}^{2}\right]$ \\
\hline$I_{z}$ & $0.0550\left[\mathrm{kgm}^{2}\right]$ \\
\hline$I_{x z}$ & $0.00022\left[\mathrm{kgm}^{2}\right]$ \\
\hline & \\
\hline
\end{tabular}

\subsection{Model matematyczny}

Samolot Delta przyjęty do badań jest obiektem symetrycznym względem płaszczyzny $x-z$ dlatego też tensor bezwładności może zostać zapisany jako:

$$
I=\left(\begin{array}{ccc}
I_{x} & 0 & -I_{x z} \\
0 & I_{y} & 0 \\
-I_{x z} & 0 & I_{z}
\end{array}\right)
$$

Równania kinematyki i dynamiki dla ruchu postępowego mogą zostać zapisane następująco $[14,15]$ :

$$
\begin{aligned}
& \dot{x}=\cos \theta \cos \psi u+(\sin \phi \sin \theta \cos \psi-\cos \phi \sin \psi) v+ \\
& +(\cos \phi \sin \theta \cos \psi+\sin \phi \sin \psi) w \\
& \dot{y}=\cos \theta \sin \psi u+(\sin \phi \sin \theta \sin \psi-\cos \phi \cos \psi) v+ \\
& (\cos \phi \sin \theta \sin \psi-\sin \phi \cos \psi) w \\
& \dot{z}=\sin \theta u-\sin \phi \cos \theta v-\cos \phi \cos \theta w \\
& \dot{u}=r v-g w-q \sin \theta+C_{X}(x, \delta) \\
& \dot{v}=p v-r u+g \cos \theta \sin \phi+C_{Y}(x, \delta)
\end{aligned}
$$




$$
\dot{w}=q u-p v+g \cos \theta \cos \phi+C_{Z}(x, \delta),
$$

W podobny sposób możemy zapisać równania kinematyki i dynamiki dla ruchu obrotowego [14]:

$$
\begin{aligned}
& \dot{\phi}=p+q \sin \phi \tan \theta+r \cos \phi \tan \theta \\
& \dot{\theta}=q \cos \phi-r \sin \phi \\
& \dot{\psi}=q \sin \phi \frac{1}{\cos \theta}+r \cos \phi \frac{1}{\cos \theta} \\
& \dot{p}=\hat{I}_{1} p q-\hat{I}_{2} q r+\frac{1}{2} \rho V^{2} S \frac{b}{2}\left[\begin{array}{c}
\left.C_{p 0}+C_{p \beta} \beta+C_{p p} \frac{b p}{2 V}+C_{p r} \frac{b r}{2 V}+\right] \\
+C_{p_{\delta_{a}}} \delta_{a}+C_{p_{\delta_{r}}} \delta_{r}
\end{array}\right] \\
& \dot{q}=\frac{I_{x z}}{I_{y}}\left(r^{2}-p^{2}\right)+\frac{I_{z}-I_{x}}{I_{y}} p r+\frac{1}{2 I_{y}} \rho V^{2} \bar{c} S\left[\begin{array}{c}
C_{m 0}+C_{m_{\alpha}} \alpha+ \\
+C_{m q} \frac{\bar{c} q}{V}+C_{m_{e}} \delta_{e}
\end{array}\right] \\
& \dot{r}=\hat{I}_{3} p q-\hat{I}_{4} q r+\frac{1}{2} \rho V^{2} S \frac{b}{2}\left[\begin{array}{c}
C_{r 0}+C_{r_{\beta}} \beta+C_{r_{p}} \frac{b p}{2 V}+C_{r_{r}} \frac{b r}{2 V}+ \\
+C_{r_{\delta_{a}}} \delta_{a}+C_{r_{\delta_{r}}} \delta_{r}
\end{array}\right]
\end{aligned}
$$

gdzie: $\alpha$ - kąt natarcia; $\beta$ - kąt ślizgu; $S$ - powierzchnia skrzydła; $b$ - rozpiętość skrzydła; $\bar{c}$ - średnia cięciwa, $\hat{I}_{1,2,3,4}$ - stałe zależne od $I$.

\subsection{Układ sterowania}

W oparciu o przedstawiony powyżej model dynamiki pojedynczego obiektu (mikro-samolotu) został zbudowany model symulacyjny w środowisku Matlab/Simulink (z użyciem przyborników Control [16], Flight Dynamics and Control [17] oraz Aerospace [18]) zawierający pętle stabilizacyjne, sterowania i nawigacyjne mikro-samolotu oraz dodatkowe elementy takie jak układ śledzenia linii drogi, układ generowania linii drogi oraz układ planowania linii drogi (rys. 2). Zarówno Leader jak i Follower posiadał identyczny układ sterowania. Architektura całego układu sterowania została pokazana na rysunku 3. 


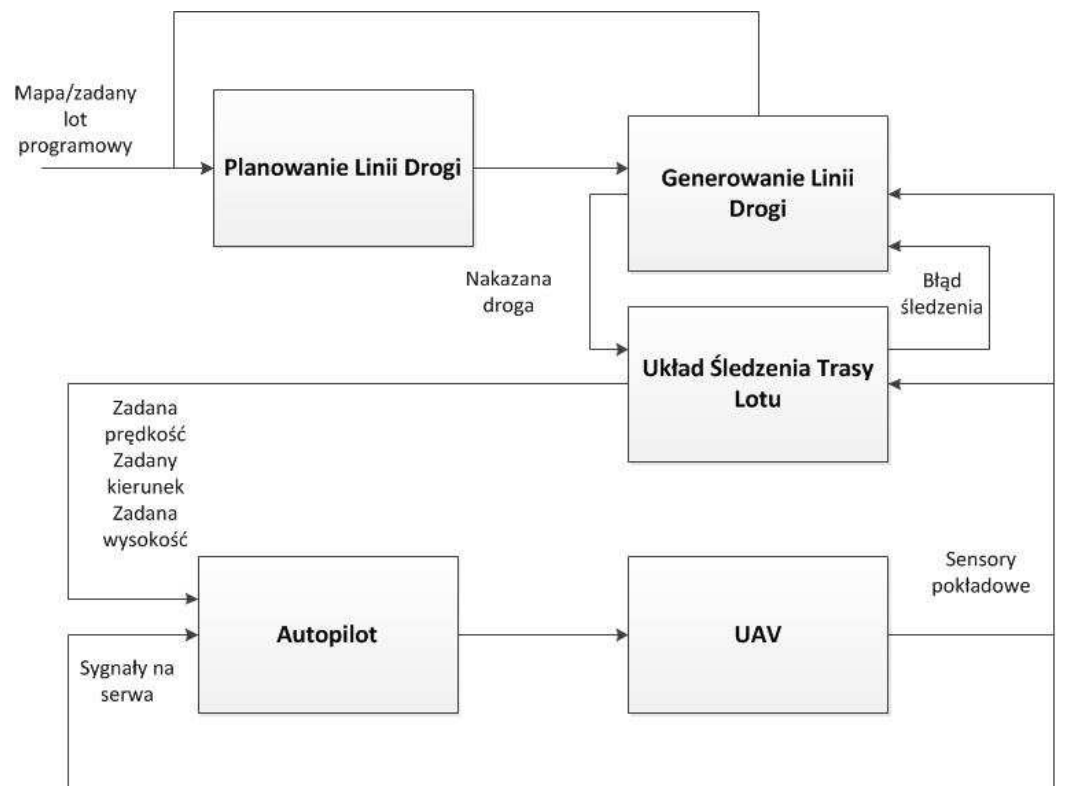

Rys. 2. Architektura układu sterowania pojedynczego obiektu

Fig. 2. Architecture of the single object control system

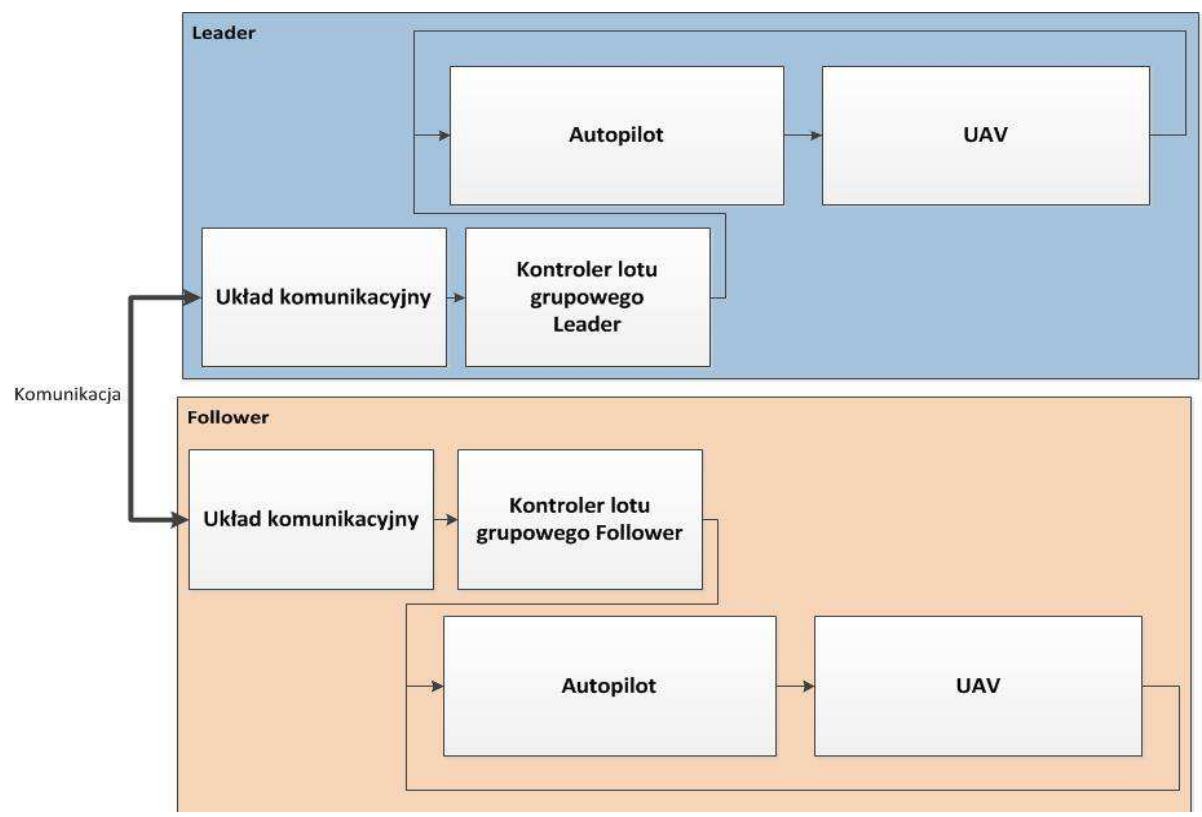

Rys. 3. Schemat układu symulacyjnego

Fig. 3. Scheme of the simulative system 


\section{Sterowanie lotem grupowym}

Wybrany układ sterowania lotem grupowym opiera się o koncepcję Leader/Follower. Analizowany był układ z jednym Leaderem oraz jednym obiektem śledzącym. Prawa sterowania opierają się na wyliczanych błędach pozycji pomiędzy Leader'em a Follower'em. Mogą one zostać zapisane następująco:

$$
\left[\begin{array}{l}
e_{x} \\
e_{y} \\
e_{h}
\end{array}\right]=\left[\begin{array}{l}
x_{L}-x_{F} \\
y_{L}-y_{F} \\
h_{L}-h_{F}
\end{array}\right]
$$

gdzie: $e_{x, y, h^{-}}$błędy w kierunku $x, y$ i $z ; x_{L, F}$ - położenie Leader'a i Follower'a w kierunku $x ; y_{L, F}$ - położenie Leader'a i Follower'a w kierunku y; $h_{L}$ - wysokość lotu Leader'a, $h_{F}$ - wysokość lotu Follower'a.

Układ sterowania lotem grupowym wylicza zadane wartości kierunku $\psi_{Z}$, prędkości $v_{Z}$ i wysokości $h_{Z}$ w oparciu o (14) zgodnie z równaniami:

$$
\begin{aligned}
& \psi_{Z}=k_{p \psi}\left[R_{\psi_{L}}\left(e_{x}-x_{z}\right)\right]+\psi_{L Z} \\
& v_{Z}=k_{p v}\left[R_{\psi_{L}}\left(e_{y}-y_{z}\right)\right]+v_{L Z} \\
& h_{Z}=k_{p h}\left[R_{\psi_{L}}\left(e_{z}-h_{z}\right)\right]+h_{L Z}
\end{aligned}
$$

gdzie $k_{p \psi}$ - wzmocnienie regulatora kierunku; $k_{p v}$ - wzmocnienie regulatora prędkości; $k_{p h}$ - wzmocnienie regulatora wysokości; $R_{\psi_{L}}$ - macierz obrotu; $x_{z}$ , $y_{z^{-}}$zadana odległość pomiędzy Leader'em a Follower'em w kierunku $x, y$ i zadana różnica wysokości $h_{z}, \psi_{L Z}$ - zadany kierunek Leader'a; $v_{L Z}$ - zadana prędkość Leader'a; $h_{L Z}$ - zadana wysokość Leader'a.

\section{Wyniki badań}

$\mathrm{W}$ trakcie prowadzonych badań symulacyjnych w pierwszym etapie lotu Leader i Follower posiadali odmienne nakazane drogi lotu. Badaną funkcją było krążenie wokół punktu po okręgu o zadanym promieniu. Zadane promienie Leader'a i Follower'a posiadały znacznie różniące się wartości. Start odbywał się bez włączonej funkcji śledzenia Leadera. Follower powinien być przesunięty względem Leadera o wartości $\mathrm{x} \_\mathrm{z}=10[\mathrm{~m}], \mathrm{y} \_\mathrm{z}=40[\mathrm{~m}], \mathrm{h} \_\mathrm{z}=0[\mathrm{~m}]$. Po czasie 10 sekund układ sterowania Follower'a przełączany był automatycznie w tryb śledzenia. Wyniki przeprowadzonych symulacji zostały zamieszczone na rysunkach $4 \div 6$ gdzie zamieszczono przykłady śledzenia Leader'a dla różnych wartości promieni okręgów Leader’a. 


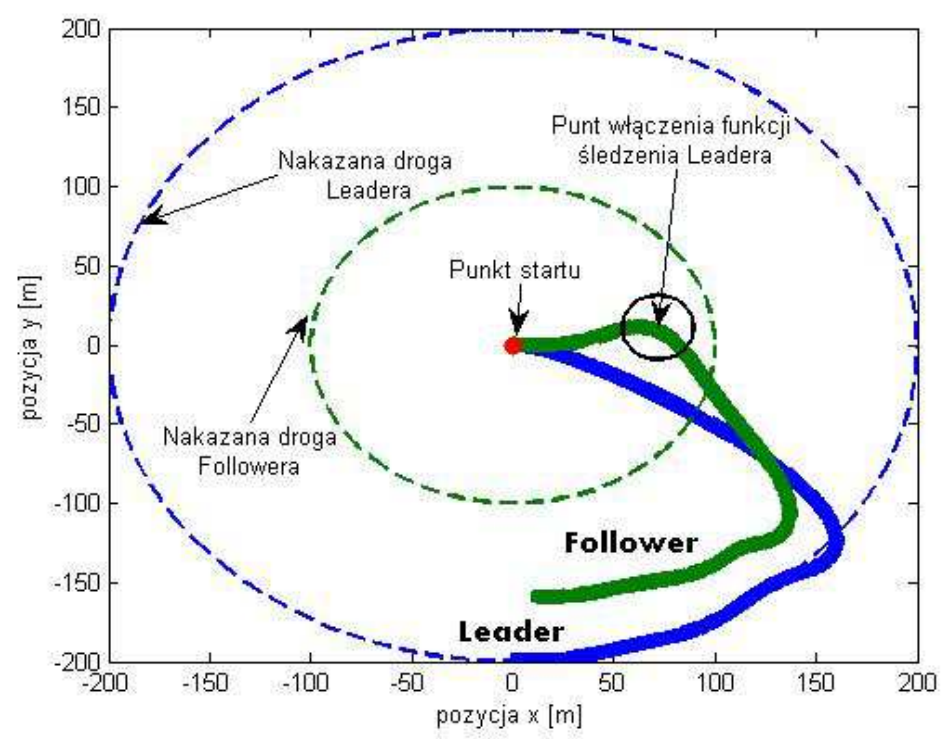

Rys. 4. Śledzenie Leader'a (promień okręgu $200 \mathrm{~m}$ )

Fig. 4. Leader's tracking (the diameter of a circle is $200 \mathrm{~m}$ )

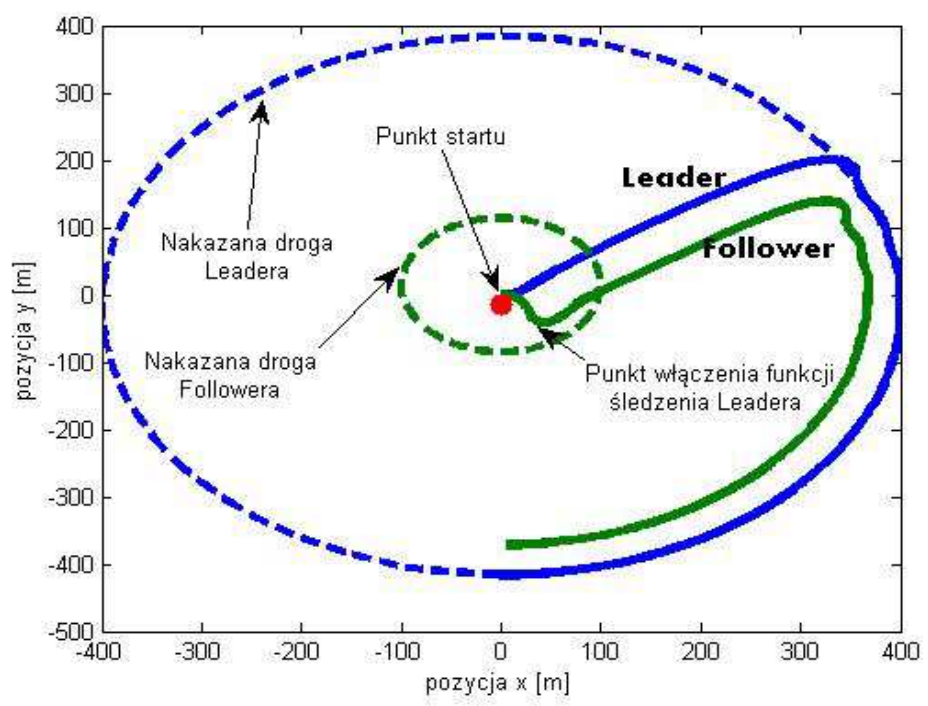

Rys. 5. Śledzenie Leader'a (promień okręgu $400 \mathrm{~m}$ )

Fig. 5. Leader's tracking (the diameter of a circle is $400 \mathrm{~m}$ ) 


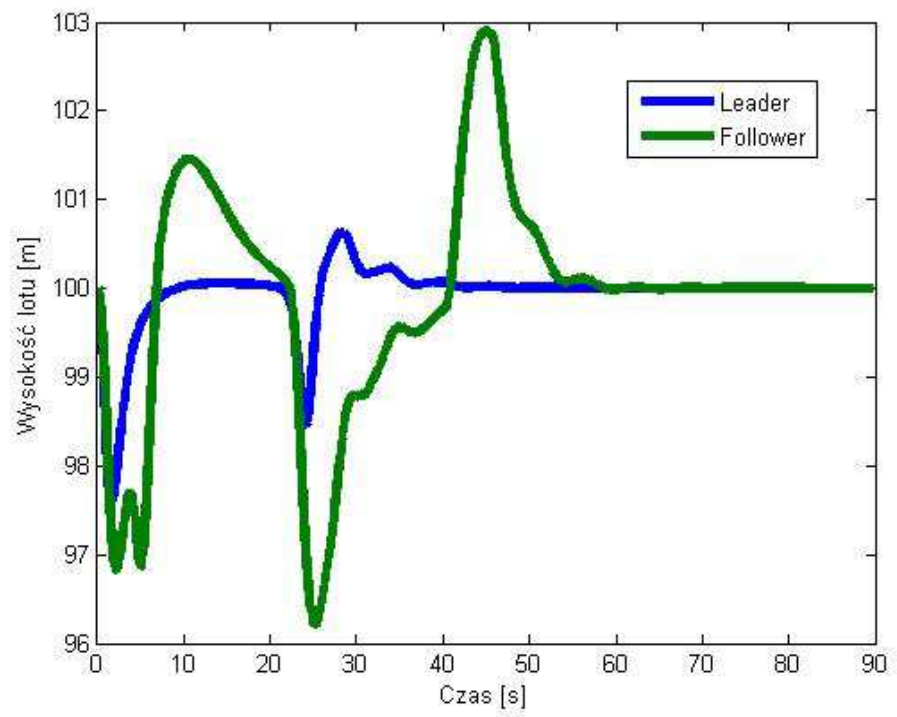

Rys. 6. Wysokość lotu Leader'a i Follower'a podczas śledzenia

Fig. 6. Flight altitude of Leaded's and Follower's while tracking

\section{Podsumowanie}

W artykule przedstawiony został problem sterowania lotem grupowym bezzałogowych aparatów latających. Opisany został model matematyczny mikro-samolotu, opracowane prawa sterowania dla procesu śledzenia Leadera oraz przeprowadzone badania symulacyjne. Pozwalają one stwierdzić, że zaprojektowane prawa sterowania umożliwiają sterowanie obiektem podążającym za Leader'em. Na rys. 4 przedstawiającym drogę Leader'a oraz Follower'a widzimy, że drogi te przecinają się. Jednakże przełączenie w tryb śledzenia Leader'a następuje zawsze gdy drugi samolot jest ustawiony za Leader'em i ma on za zadanie bezwzględne trzymanie się ,z tyłu” pierwszego obiektu (jest to uwzględnione w układzie sterowania). Dalszym krokiem prac będzie sprawdzenie $\mathrm{w}$ drodze symulacji komputerowej oraz podczas prób w locie opracowanego algorytmu naprowadzania na Leadera połączonego $\mathrm{z}$ algorytmem śledzenia Leader'a pokazanym w niniejszym artykule.

\section{Literatura}

[1] Giulietti F., Pollini L., Innocenti M.: Autonomous Formation Flight, IEEE Control System Magazine, 20 (2000) 34-44. 
[2] Wan S., Campa G., Napolitano M.R., Seanor B., Gu Y.: design of formation control laws for research aircraft models, AIAA Guidance, Navigation and Control Conference and Exhibit, Austin, USA 2003, AIAA article number 2003-5730.

[3] Gingras D. R., Player J. L., and Blake,W. B.: Static and dynamicwind tunnel testing of airvehicles in close proximity, AIAA Paper 2001-4137, 2001.

[4] Ray R.J., Cobliegh B.R., Vachon M J., Clinton St. J.: Flight test techniques used to evaluate performance benefits during formation flight, NASA/TP-2002-210730, 2002.

[5] Iglesias S., Mason W. H.: Optimum spanloads in formation flight, AIAA Paper 2002-0258, 2002.

[6] Scharaf D.P., Hadaeg F.Y., Ploen S.R.: A Survey of spacecraft formation flying guidance and control (Part II): Control, Proc. American Control Conference, Boston 2004.

[7] McCammish S., Pachter M., D’Azzo J. J., Reyna V.: Optimal formation flight control, AIAA Guidance, Navigation and Control Conference, 1996.

[8] Boskovic J.D., Sun Z., Song Y.D., An adaptive reconfigurable formation flight control design, Proc. American Control Conference, Ohio 2003, pp. 284-289.

[9] Li B., Liao X.H., Sun Z., Li Y., Song Y.D.: Robust autopilot for close formation flight of multi-UAVs, system theory, Proc. 38th Southeastern Synposium, Cookeville 2006, pp. 258-262

[10] Schumacher C.J., Singh S.N.: Nonlinear control of multiple UAVs in closecoupled formation flight, AIAA paper, 2000.

[11] Kondratiuk M.: The simulation research on aerodynamic characteristics of the micro delta wing UAV with mechanical barriers located near edges of attack (in Polish), Acta Mech. Automatica, 4 (2010) 54-59.

[12] Ambroziak L., Gosiewski Z., Kondratiuk M.: Aerodynamics characteristics identification of micro air vehicle (in Polish), Trans. Institute Aviation, 216 (2011) 1729.

[13] Mystkowski A., Robust control of micro UAV dynamics with an autopilot, J. Theor. Appl. Mech., 51 (2013) 751-761.

[14] Knoebel N.B., Osborne S.R., Matthews J.S., Eldredge A.M., Beard R.W.: Computationally simple model reference adaptive control for miniature air vehicles, Proc. American Control Conference, Minneapolis, Minesota 2006, pp. 5978-5983.

[15] Kaniewski P.: Struktury, modele i algorytmy w zintegrowanych systemach pozycjonujących i nawi-gacyjnych, Wyd. WAT, Warszawa 2010.

[16] Control System Toolbox User's Guide 2013b Mathworks.

[17] FDC 1.2 - A Simulink Toolbox for Flight Dynamic and Control Analysis, 2001.

[18] Aerospace Blockset for use with Simulink User's Guide 2013b Mathworks.

Publikacja wspótfinansowana ze środków stużacych rozwojowi młodych naukowców i doktorantów w ramach pracy o numerze W/WM/1/2013. 


\title{
FORMATION FLIGHT CONTROL LAWS DEVELOPMENT FOR UNMANNED AERIAL VEHICLES
}

\begin{abstract}
S u m m a r y
Unmanned flying machines (UFM) are currently used by people for a variety of military and civilian tasks. For example, here can be mentioned such tasks as reconnaissance and exploration of the territory of the enemy, damage assessment after the hostilities, traffic control, patrolling the country borders, monitoring of agricultural crops, counting wild animals over large areas of forest and many others. All these tasks can be performed faster and more efficiently by a UFM formation together with a common control law. Imple-mentation of control laws of formation flight should be preceded by a thorough analysis of the created control algorithm, and simulation study that allows to verify the proposed approach. The article presents the problem of flight control of UFM formation. The developed method of the flight control of UFM for-mation flight based on the Leader / Follower configuration is presented. Based on the established model of the dynamics of a single object (micro-aircraft) the simulation model was built in Matlab / Simulink envi-ronment using Control, Flight Dynamics and Control, and Aerospace toolboxes. The mathematical basis of this method and the designing process of UFM formation control laws have been presented. Then, a verifi-cation of designed control laws has been done. A series of simulation tests and their results are presented in the form of charts showing waveforms of both Leader's and Follower's navigational parameters (speed, direction, altitude, flight path, flight profile). The obtained results allow to evaluate correctly the accepted design process of control laws and its effectiveness and the ability to implement on the on-board computer of the micro-plane.
\end{abstract}

Key words: unmanned aerial vehicles, flight control, navigable parameters

DOI: $10.7862 / \mathrm{rm} .2014 .2$

Otrzymano/received: 15.05.2013

Zaakceptowano/accepted: 7.01.2014 